\title{
Impact of a centralized osteoporosis coordinator on post-fracture osteoporosis management: a cluster randomized trial
}

\author{
S. B. Jaglal • O. S. Donescu • V. Bansod • J. Laprade • K. Thorpe • G. Hawker • \\ S. R. Majumdar • L. Meadows - S. M. Cadarette - A. Papaioannou • M. Kloseck • \\ D. Beaton • E. Bogoch • M. Zwarenstein
}

Received: 16 March 2011 / Accepted: 1 June 2011 / Published online: 16 July 2011

(C) The Author(s) 2011. This article is published with open access at Springerlink.com

\begin{abstract}
Summary We conducted a cluster randomized trial evaluating the effect of a centralized coordinator who identifies and follows up with fracture patients and their primary care physicians about osteoporosis. Compared with controls, intervention patients were five times more likely to receive BMD testing and two times more likely to receive appropriate management.

Introduction To determine if a centralized coordinator who follows up with fracture patients and their primary care physicians by telephone and mail (intervention) will increase the proportion of patients who receive appropri-
\end{abstract}

S. B. Jaglal • O. S. Donescu • V. Bansod

Toronto Rehabilitation Institute,

Toronto, ON, Canada

S. B. Jaglal $(\bowtie) \cdot J$. Laprade

Department of Physical Therapy, University of Toronto,

160-500 University Avenue,

Toronto, ON M5G 1V7, Canada

e-mail: susan.jaglal@utoronto.ca

K. Thorpe

Li Ka Shing Knowledge Institute, St. Michael's Hospital,

Toronto, ON, Canada

G. Hawker

Department of Medicine, University of Toronto,

Toronto, ON, Canada

S. R. Majumdar

Department of Medicine, University of Alberta,

Edmonton, AB, Canada

L. Meadows

Department of Family Medicine, University of Calgary,

Calgary, AB, Canada ate post-fracture osteoporosis management, compared to simple fall prevention advice (attention control).

Methods A cluster randomized controlled trial was conducted in small community hospitals in the province of Ontario, Canada. Hospitals that treated between 60 and 340 fracture patients per year were eligible. Patients 40 years and older presenting with a low trauma fracture were identified from Emergency Department records and enrolled in the trial. The primary outcome was 'appropriate' management, defined as a normal bone mineral density (BMD) test or taking osteoporosis medications.

\section{S. M. Cadarette}

Leslie Dan Faculty of Pharmacy,

University of Toronto,

Toronto, ON, Canada

A. Papaioannou

Department of Medicine,

McMaster University,

Hamilton, ON, Canada

M. Kloseck

Health and Rehabilitation Sciences,

University of Western Ontario,

London, ON, Canada

D. Beaton · E. Bogoch

Mobility Program Clinical Research Unit,

St. Michael's Hospital,

Toronto, ON, Canada

M. Zwarenstein

Institute for Clinical Evaluative Sciences,

Toronto, ON, Canada 
Results Thirty-six hospitals were randomized to either intervention or control and 130 intervention and 137 control subjects completed the study. The mean age of participants was $65 \pm 12$ years and $69 \%$ were female. The intervention increased the proportion of patients who received appropriate management within 6 months of fracture; $45 \%$ in the intervention group compared with $26 \%$ in the control group (absolute difference of $19 \%$; adjusted OR, 2.3; 95\% CI, 1.3-4.1). The proportion who had a BMD test scheduled or performed was much higher with $57 \%$ of intervention patients compared with $21 \%$ of controls (absolute difference of $36 \%$; adjusted OR, 4.8; 95\% CI, 3.0-7.0).

Conclusions A centralized osteoporosis coordinator is effective in improving the quality of osteoporosis care in smaller communities that do not have on-site coordinators or direct access to osteoporosis specialists.

Keywords Case management . Cluster randomized trial . Fractures $\cdot$ Osteoporosis $\cdot$ Secondary prevention

\section{Introduction}

Prevention of osteoporotic fractures depends on the identification of individuals at risk for fractures, followed by interventions to reduce this risk, such as modification of lifestyle factors and use of bone-sparing medications $[1,2]$. The presence of a low trauma fracture is a significant risk factor for predicting future fracture; about $50 \%$ of those that survive experience a subsequent fracture in 10 years [3]. Clinical practice guidelines state that a low trauma fracture should signal the opportunity to initiate osteoporosis treatment for prevention of subsequent fractures $[1,2]$.

Two systematic reviews concluded that despite the availability of effective treatment options, the majority of patients who experience a low trauma fracture are underinvestigated and under-treated for osteoporosis, within Canada and internationally [4, 5]. This highlights an important care gap [6]. In Europe and North America, the care gap has resulted in action plans to improve bone health [7-10]. One such plan, currently being implemented, is the Ontario Osteoporosis Strategy, a population-based chronic disease management program [10]. The overall goal is to reduce morbidity, mortality and costs from osteoporosis and related fractures by raising public awareness, changing knowledge, attitudes and behaviours of both the public and health professionals and improving prevention and treatment programs.

Secondary fracture prevention is a major focus with a province-wide Fracture Clinic Screening Program implemented in 36 medium- and high-volume fracture clinics. Based on the Osteoporosis Exemplary Care Program developed by Bogoch et al. [11], Screening Coordinators conduct an osteoporosis assessment, provide education, refer low trauma fracture patients to their primary care physician for follow-up and send a letter recommending that the patient be assessed for osteoporosis with bone mineral density (BMD) testing. Unfortunately, by restricting the Osteoporosis Strategy coordinators to medium and large volume hospitals with fracture clinics, the program misses about one third of fracture patients in Ontario who are treated in small community hospitals as funding an osteoporosis coordinator is not justifiable in each small community hospital. Yet, similar to others [12, 13], we have previously shown that an educational intervention alone was not sufficient to improve practice [14], suggesting the need for a more targeted intervention in smaller communities. There have been a number of recent randomized controlled trials of post-fracture care interventions that have reported positive effects [15-23] with a pooled absolute improvement in osteoporosis treatment rates of $20 \%$ over and above usual care [24]. However, in all of these trials the majority of patients were recruited from academic centres or health maintenance organizations with high fracture volumes and access to osteoporosis specialists.

The current cluster randomized trial was conducted to determine if an intervention based on the osteoporosis coordinator role in the focused environment of a highvolume urban fracture clinic can be effective when adapted to smaller community hospitals. We hypothesized that a centralized coordinator who identifies and follows up with fracture patients and their primary care physicians by telephone and mail will increase the proportion of patients who receive appropriate investigation and treatment for osteoporosis compared with simple fall prevention advice among patients.

\section{Methods}

Study design

We conducted a cluster randomized trial in which the hospital emergency department was the unit (cluster) of allocation and men and women with a low trauma fracture were the unit of analysis. Since the purpose of the trial was to change practice behaviour and patients in these communities were likely to have the same primary care physician, a cluster design was chosen to minimize contamination.

Setting and participants

\section{Hospital eligibility criteria and recruitment}

Hospitals without a dedicated osteoporosis screening coordinator that treated more than 60 fracture patients 
per year in their Emergency Department (ED) and who were members of the Ontario Telemedicine Network were potentially eligible $(n=54)$. Information letters were sent to the hospitals explaining the study and site visits were conducted by the centralized coordinator. Ethics approval was obtained from the Research Ethics Board of the Toronto Rehabilitation Institute and each of the participating sites.

\section{Patient eligibility criteria and recruitment}

Emergency Department records provided through the National Ambulatory Care Reporting System database at each hospital site were used to identify all new cases of fracture. Records of patients 40 years and older presenting with a fracture of the hip, forearm, wrist, $\operatorname{rib}(\mathrm{s})$, sternum, thoracic and lumbar spine, shoulder and upper arm, pelvis, lower leg and ankle were identified. Patients with 'cause of injury' codes indicating the fracture was not likely due to a fall from a standing height (e.g. transportation accidents or other major trauma), who were residing in a nursing home, or with fractures that occurred more than 3 months between the time of their initial ED visit and preparation of the list for the centralized coordinator were excluded. On a monthly basis, a list of fracture patients was provided to the centralized coordinator. Participants were recruited by telephone between January and July 2008 and further screened with the following exclusion criteria: unable to contact, died, in long-term care, cognitive or hearing impairment, lived outside of region and previously screened by an Osteoporosis Strategy coordinator at another hospital.

\section{Intervention}

The multi-faceted intervention was comprised of having the centralized coordinator, a physical therapist, follow-up with fracture patients and their physicians to provide evidencedbased recommendations about fracture risk and osteoporosis treatment and assist with arranging telehealth consultations to the Multidisciplinary Osteoporosis Program (MOP) [25] at a teaching hospital for complex patients if requested.

\section{Patient component}

In the intervention arm, the centralized coordinator phoned fracture patients and counselled them about their risk of osteoporosis, the need to follow-up with their primary care physician to discuss osteoporosis and the need for a BMD test and provided information about existing resources for osteoporosis management. A standard baseline questionnaire was completed, and consent was obtained for the research assistant to contact them and collect follow-up data. Each patient was sent a personalized letter reiterating the conversation. Three months later, they received a reminder phone call from the coordinator and were encouraged to follow-up with their primary care physician if they had not already done so. At 6 months, patients completed a follow-up questionnaire administered by the research assistant who was blinded to treatment allocation.

\section{Physician component}

The centralized coordinator sent the patient's primary care physician a letter informing them that their patient had experienced a fracture. The letter was tailored for each patient and highlighted: (1) the patient's high risk for osteoporosis and need for a BMD test if one has not been done in the past 6 months, (2) high 1-year fracture risk in the presence of fracture and BMD T-score is $\leq 1.5$ if the patient goes untreated [26], (3) efficacy of first-line treatment with bisphosphonates on fracture risk, and (4) availability of osteoporosis specialist consultation through the MOP if desired. Physicians were asked to place the letter in the patient's office chart as a point-of-care reminder for the next visit. Primary care physicians also received pocket cards containing evidencebased recommendations about appropriate BMD testing and treatment based on the most recent Canadian guidelines available at the time of the trial $[1,27]$.

\section{Attention controls}

Similar to the intervention hospitals, within 3 months of the ED visit for fracture, patients from the control hospitals received educational material and telephone counseling regarding fall prevention and home safety from the centralized coordinator. Patients were encouraged to visit their primary care physician for a more detailed advice and medication review. They did not receive counseling or educational materials about osteoporosis. The coordinator administered the baseline questionnaire and obtained consent for the research assistant to collect follow-up data at 6 months. The control group did not receive the 3month reminder phone call.

\section{Outcomes and measurements}

The primary outcome was the proportion of patients selfreporting 'appropriate management', defined as receiving, within 6 months of fracture, either an osteoporosis medication (bisphosphonate, raloxifene or teriparatide) or normal BMD and prevention advice. Previous research has shown excellent agreement between self-report and dispensing records for osteoporosis medications [28, 29] and self-report for having had a BMD test [30]. This composite outcome was chosen because unlike the other post-fracture care trials that excluded patients already taking osteoporosis medications [15-23], this trial included patients who were 
already on treatment for osteoporosis when they experienced a low trauma fracture. The Canadian guidelines recommended that these patients should have their BMD reassessed and medications reviewed [1,27]. Secondary outcomes were: the proportion of patients with a physician visit to discuss osteoporosis after fracture, and the proportion for which BMD was scheduled or performed.

\section{Sample size}

The sample size was based on a binary outcome (appropriate management-yes/no). In a survey of osteoporosis researchers and clinicians from Canada and the USA, the median response reported for a 'minimal clinically important difference' for a post-fracture care intervention was $20 \%$ over and above 'usual care' [31]. From our demonstration project in five small communities in Ontario [14], we found that $31 \%$ of patients had a BMD test after fracture. We anticipated a cluster size of ten patients per hospital and an intra-cluster correlation coefficient of 0.01 [32]. Therefore, we needed to identify about 20 fracture patients in each of 30 hospitals to detect an effect size of $20 \%$ (intervention $=50 \%$ and controls $=$ $30 \%$ ) with $90 \%$ power. Therefore, the final sample was at least 300 patients (ten patients per cluster with 15 intervention and 15 control clusters). The level of statistical significance was set at $p<0.05$.

\section{Randomization}

Hospitals that agreed to participate were assigned by simple random allocation to invention or attention control. Randomization was performed with a computer program by the statistician who was blind to the hospitals' identity. The investigators and the research assistant collecting the outcome information were blinded to treatment allocation

\section{Statistical analyses}

To assess the quality of randomization, demographic and clinical characteristics in the intervention and control groups were calculated using descriptive statistics. To assess for differences between outcomes in the intervention and control groups, multi-level hierarchical modelling using the General Estimating Equation (GEE) approach was used to account for clustering to estimate the treatment effect as an odds ratio and test for significance [33, 34]. First-order interaction terms (specifically: sex by intervention status) were evaluated. The 95\% confidence intervals and $p$ values were calculated using the sandwich estimator of variance. The analysis was carried out using R: A Language and Environment for Statistical Computing version 2.10.1 [35, 36]. The GEE models were fit using the $R$ package geepack version 1.0-17.

\section{Results}

Study flow

Of the 54 eligible hospitals, 36 agreed to participate and were randomly assigned to intervention or control group (18 in each group). We obtained 801 records for fracture patients within 3 months of their admission to the ED; 139 were received 3 months after fracture. Of these, 443 were excluded: 298 were unable to reach, 51 had died or were in long-term care, 43 lived outside of the hospital catchment area, 21 refused, 18 had previously been screened by a fracture clinic coordinator and 12 had significant cognitive or hearing impairment, resulting in 358 enrolled subjects (Fig. 1).

Cluster size was comparable between the groups with ten (range, 3-16) in the intervention and ten (range, 4-18) in the control hospitals. Of those randomized, 52 from the intervention hospitals and 39 from the control hospitals were lost to follow-up leaving a total of 267 subjects with complete data for analysis. The primary analysis is a 'complete case' and includes only those whose outcome is known [37]. A secondary analysis was the strict intention to treat analysis in which all randomized subjects were included.

\section{Baseline characteristics}

The mean age of the study participants was 66.0 years in the intervention and 65.4 in the control group; about two thirds were female and married. Twenty-seven percent had a history of a previous fracture since the age of 40 years, $20 \%$ were current smokers and $23 \%$ had fallen in the previous 12 months. Thirty-one percent had a BMD test in the previous 12 months, $25 \%$ self-reported a diagnosis of osteoporosis and $19 \%$ were currently taking osteoporosis medications. The most common fracture type was wrist (34\%), followed by ankle (16\%), rib (12\%), shoulder $(12 \%)$ and hip (8\%). There was no significant difference in demographic and clinical characteristics among patients in the intervention and control groups (Table 1).

\section{Outcomes}

The intervention increased the proportion of patients who received appropriate management, defined as taking an osteoporosis medication or normal BMD and prevention advice within 6 months of fracture: $45 \%(59 / 130)$ in the intervention group compared with $26 \%(35 / 137)$ in the control group, giving an absolute difference of $20 \%$; cluster-adjusted OR, 2.3; 95\% CI, 1.3-4.1; $p=0.003$ (Table 2). Of the $45 \%$ in the intervention group appropriately managed, $23 \%$ had normal BMD and $22 \%$ were on treatment and of the $26 \%$ in the control group, $9 \%$ had normal BMD and $17 \%$ were on treatment. The proportion 
Fig. 1 Flow of patients through the trial

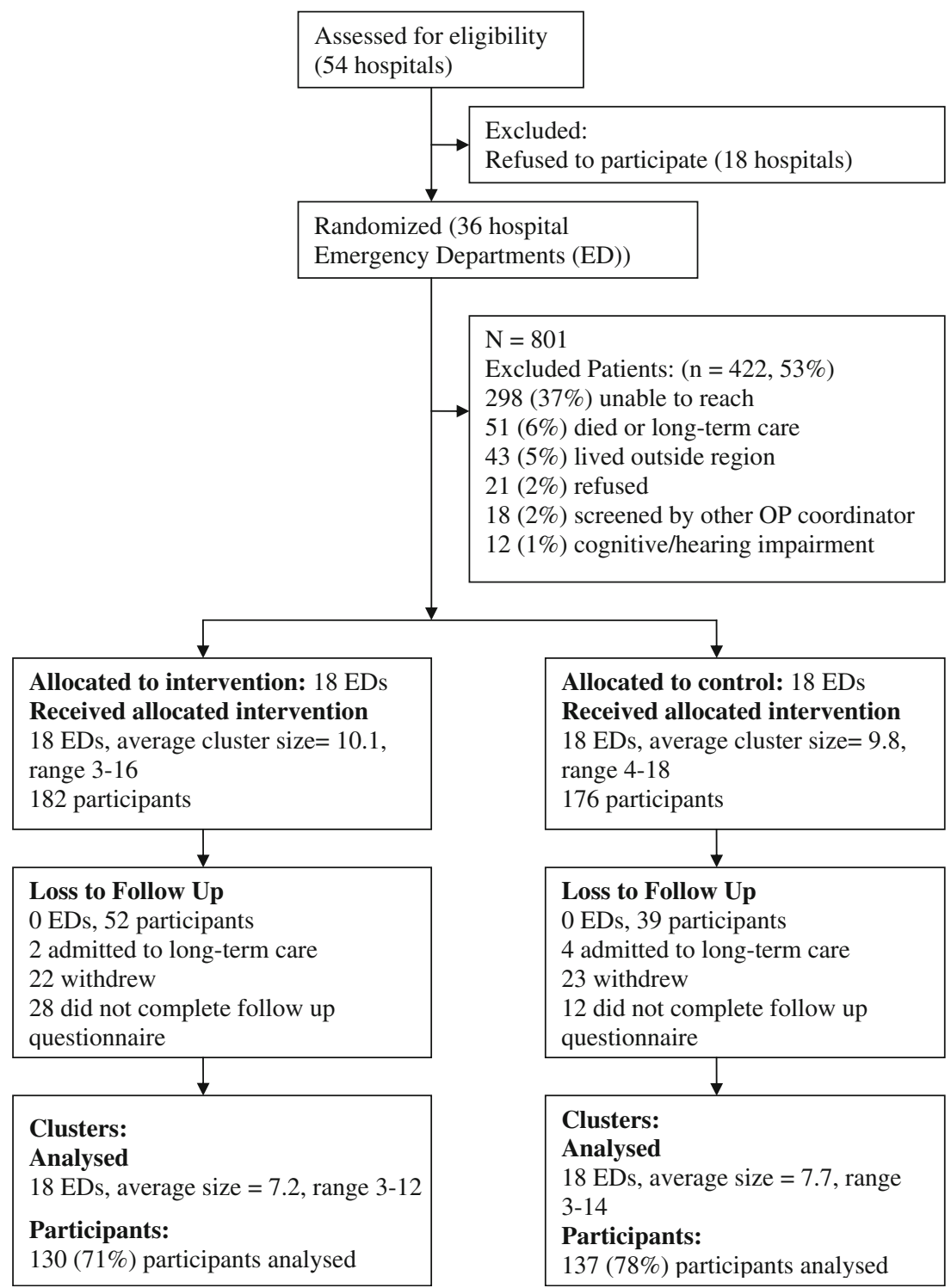

who had a BMD test scheduled or performed was much higher $(57 \%$ of intervention patients compared with $21 \%$ of controls; cluster-adjusted OR, 4.8; 95\% CI, 3.0-7.0; $p<$ $0.0001)$. The intervention resulted in the majority of patients having a discussion about osteoporosis with their physician: $82.2 \%$ intervention compared with $55.4 \%$ control patients; cluster-adjusted OR, 3.8; 95\% CI, 2.3$6.3 ; p<0.0001$. For the strict intention to treat analysis in which all randomized subjects are included, the corresponding proportions for appropriate management are $32 \%(59 / 182)$ in the intervention and 20\% (35/176) in the control, $p=0.007$.

Male and female differences

For each of the three outcomes in the hierarchical modelling a test for an intervention by sex interaction was not statistically significant. Of the 267 study participants with outcome data, $29 \%$ were male. When analyses were restricted to the intervention group, only $29 \%$ of males compared with $51 \%$ of females were appropriately managed (Table 3) while the proportions that had a BMD test scheduled or performed (50\% males compared with $59 \%$ females) and that saw their primary care physician $(76 \%$ males and $84 \%$ females) were similar.

\section{Discussion}

This cluster randomized trial in 36 small community hospitals with 267 study participants who suffered a low trauma fracture found that the multi-faceted intervention resulted in a significant increase in the proportion of patients appropriately managed within 6 months of fracture 
Table 1 Baseline demographic and clinical characteristics, $N=267$

\begin{tabular}{|c|c|c|c|}
\hline Characteristic & $N$ & $\begin{array}{l}\text { Intervention }(n=130 \\
\text { mean }(\mathrm{SD}) \text { or }(\%))\end{array}$ & $\begin{array}{l}\text { Control }(n=137 \\
\text { mean }(\mathrm{SD}) \text { or }(\%))\end{array}$ \\
\hline \multicolumn{4}{|l|}{ Demographic characteristics } \\
\hline Age in years & 267 & $66.0(11.0)$ & $65.4(11.6)$ \\
\hline Female & 267 & $96(74 \%)$ & $93(68 \%)$ \\
\hline College/university education & 265 & $50(39 \%)$ & $58(42 \%)$ \\
\hline Married & 266 & $84(65 \%)$ & $93(68 \%)$ \\
\hline Living alone & 259 & $28(23 \%)$ & $35(26 \%)$ \\
\hline Employed full-time & 266 & $32(24 \%)$ & $44(32 \%)$ \\
\hline \multicolumn{4}{|l|}{ Clinical characteristics } \\
\hline Prior fracture since age 40 & 266 & $36(28 \%)$ & $36(26 \%)$ \\
\hline Maternal history of hip fracture & 267 & $11(8 \%)$ & $8(6 \%)$ \\
\hline Current smoker & 266 & $25(19 \%)$ & $27(20 \%)$ \\
\hline Current weight (lbs - mean (SD)) & 265 & $166.2(33.2)$ & $162.5(34.7)$ \\
\hline History of falls in past 12 months & 266 & $29(22 \%)$ & $33(24 \%)$ \\
\hline $\begin{array}{l}\text { Have trouble getting out of chair or } \\
\text { unsteady when walking }\end{array}$ & 267 & $23(18 \%)$ & $22(16 \%)$ \\
\hline Oral steroid use for $>3$ months & 265 & $11(8 \%)$ & $4(3 \%)$ \\
\hline Rheumatoid arthritis & 265 & $4(3 \%)$ & $2(1 \%)$ \\
\hline More than 2 alcoholic drinks daily & 263 & $5(4 \%)$ & $0(0 \%)$ \\
\hline Osteoporosis diagnosis & 265 & $31(24 \%)$ & $36(27 \%)$ \\
\hline Currently taking osteoporosis medications & 267 & $25(19 \%)$ & $26(19 \%)$ \\
\hline Bone mineral density test in past 12 months & 265 & $38(29 \%)$ & $44(32 \%)$ \\
\hline Fracture type & 267 & & \\
\hline Wrist & & $48(37 \%)$ & $44(32 \%)$ \\
\hline Ankle & & $16(12 \%)$ & $26(19 \%)$ \\
\hline Rib & & $16(12 \%)$ & $15(11 \%)$ \\
\hline Shoulder & & $15(11 \%)$ & $15(11 \%)$ \\
\hline Hip & & $12(9 \%)$ & $9(6 \%)$ \\
\hline Tibia/fibula & & $7(5 \%)$ & $13(9 \%)$ \\
\hline Humerus & & $5(4 \%)$ & $3(2 \%)$ \\
\hline Spine & & $2(1 \%)$ & $2(1 \%)$ \\
\hline Pelvis & & $3(2 \%)$ & $1(1 \%)$ \\
\hline
\end{tabular}

among the intervention compared to patients in the control group, about a $20 \%$ absolute difference. The intervention also resulted in more patients having a BMD scheduled or performed and most having a discussion about osteoporosis with their primary care physician compared to patients in the control group.

To our knowledge, this is the first and only randomized trial that has been restricted to patients from small or rural communities. To date, there have been nine published postfracture care randomized controlled trials [24] that have evaluated various interventions to improve management of osteoporosis in this high-risk population. Two of these were cluster randomized trials $[19,20]$, one in a health maintenance organization with a large number of primary care practices [16], three in one or two hospitals [17, 21, 23] and four in-patient interventions for those with hip

Table 2 Primary and secondary outcomes 6 months post-fracture

\begin{tabular}{lccrr}
\hline Outcome & $\begin{array}{l}\text { Intervention } \\
(N=130(\%))\end{array}$ & $\begin{array}{l}\text { Control } \\
(N=137(\%))\end{array}$ & $\begin{array}{l}\text { Intra-cluster correlation } \\
\text { coefficient }\end{array}$ & $\begin{array}{l}\text { Adjusted odds }{ }^{\mathrm{a}} \text { ratio } \\
(95 \% \mathrm{CI})\end{array}$ \\
\hline Physician discussed osteoporosis & 82.2 & 55.4 & -0.012 & $3.8(2.3-6.3)$ \\
BMD test & 57.4 & 21.3 & -0.026 & $4.8(3.0-7.9)$ \\
Appropriate management & 45.4 & 25.9 & 0.009 & $<0.001$ \\
\hline
\end{tabular}

${ }^{\text {a }}$ Adjusted for age and sex 
Table 3 Primary and secondary outcomes among males and females by allocation to intervention or control group

\begin{tabular}{lcclcl}
\hline Outcome & \multicolumn{3}{l}{ Intervention } & & \multicolumn{2}{l}{ Control } \\
\cline { 2 - 3 } \cline { 5 - 6 } \cline { 5 - 6 } & $\begin{array}{l}\text { Males } \\
(n=34 ; \%)\end{array}$ & $\begin{array}{l}\text { Females } \\
(n=96 ; \%)\end{array}$ & & $\begin{array}{l}\text { Males } \\
(n=44 ; \%)\end{array}$ & $\begin{array}{l}\text { Females } \\
(n=93 ; \%)\end{array}$ \\
\hline $\begin{array}{c}\text { Physician discussed } \\
\text { Osteoporosis }\end{array}$ & 76.4 & 84.2 & & 59.1 & 52.7 \\
$\begin{array}{c}\text { BMD test } \\
\begin{array}{c}\text { Appropriate } \\
\text { management }\end{array}\end{array}$ & 50.0 & 59.4 & & 13.6 & 24.7 \\
\hline
\end{tabular}

${ }^{a}$ Subgroup comparison of males and females within each of intervention and control group, $p<0.05$

fracture $[15,17,18,22]$. The pooled absolute improvements across these nine trials in BMD testing was $36 \%$ and for osteoporosis treatment $20 \%$ (95\% CI, 10-30) which is virtually identical to what we observed in terms of our predefined outcome of appropriate osteoporosis management.

The interventions vary in many of the nine prior randomized trials, ranging from point-of-care reminders to physicians to patient-specific education. This is reflected in the heterogeneity seen when trying to pool results (e.g. an I2 of $88 \%$ for improvements in osteoporosis treatment) [24]. In the study by Feldstein et al. [16], the intervention was an electronic medical record reminder which resulted in $52 \%$ of intervention patients getting a BMD test or osteoporosis medication at 6 months compared with $6 \%$ of the usual care. Whereas, in the study by Majumdar et al. [21], the intervention was multi-faceted with telephonebased nurse led education, a patient-specific reminder sent to the physician and guidelines endorsed by local opinion leaders. These findings with $22 \%$ of intervention and $7 \%$ of control patients on treatment with a bisphosphonate 6 months after a wrist fracture are similar to those reported by Cranney et al. [20] who only used mailed reminders to patients and primary care physicians and a patient education package. Rozenthal et al. [23] randomized 50 distal radius fracture patients to either the orthopaedic surgeon ordering a BMD test and forwarding the results to the primary care physician or just sending a letter to the primary care physician outlining guidelines for osteoporosis screening. Initiation of osteoporosis therapy was much higher (74\%) than in other studies but this trial did not only consider treatment with bisphosphonates but also counted initiation with calcium and vitamin $\mathrm{D}$ as a treatment outcome.

We believe the key factor to the success of our intervention was that the coordinator empowered the patient to ask for a BMD test and made the patient the 'reminder' for the physician. This particular combination of a multifaceted intervention, where you have a triad of a coordinator, patient and primary care physician, should be evaluated as a model for improving guideline adherence for other chronic diseases, particularly among physicians in smaller communities with limited access to specialist care.

One of the advantages of the current trial is the ability to examine sex differences in post-fracture osteoporosis management. Previous research has shown that the care gap is significant in both men and women but more so in men [38, 39]. Our study has shown that care improved for both; however, there are still substantially greater care gaps in men versus women, as others have shown despite interventions; possible reasons are men and their physicians view osteoporosis as a disease of elderly women [40, 41] and more importantly, guidelines are unclear about treatment options. In the new 2010 Canadian guidelines, there is grade A evidence for investigating men with a fracture but grade $\mathrm{D}$ evidence for prescribing bisphosphonate therapy in men [42].

This study had a number of strengths. This was a randomized trial with a cluster design which minimized contamination because hospital sites rather than individual patients were randomized. The cluster design also increases the generalizability of the findings since the study was carried out in a large number of hospitals. This is the only randomized trial published to date of a post-fracture care intervention in rural communities without access to osteoporosis specialists and in many cases orthopaedic surgeons. One of the limitations of this study is the potential for selection bias as were unable to reach a large proportion of eligible patients. These patients were called a maximum of seven times at different times of the day and messages were left where possible. These could be individuals who were not interested in additional follow-up for their fracture, thus, limiting the generalizability of the findings. In the future, one way to improve this may be to send patients a letter informing them about the program before the coordinator calls. In addition, the loss to follow-up was greater in among intervention patients. As a result the 'complete case' analysis would potentially overestimate the impact of the intervention since those lost to follow-up in the intervention probably did not want to be contacted again if they did not comply with the coordinator's suggestions made at baseline. Another potential limitation is the lack of quality control procedures to assess treatment fidelity. The coordinator was not taped or observed when delivering the intervention. It was assumed that treatment fidelity was high given that the centralized coordinator was a physical therapist with expertise in osteoporosis management.

Our findings are also limited by the fact that we relied on self-report data, which may have biased our estimate of appropriate management since we did not have access to the actual BMD reports or patient charts. A validation study of DXA results identifies that patients underestimate bone loss, and although $84 \%$ of patients with normal BMD by 
DXA correctly identify their bones as normal, $49 \%$ with 'osteopenia' and $15 \%$ with osteoporosis also state that their bones are normal [30]. This would overestimate our findings for appropriate management. Similar to all of the other post-fracture care randomized trials, we measured 'process' outcomes, BMD testing and appropriate management, and not a clinical endpoint, such as recurrent fracture. However, receipt of a BMD test and/or use of a medication for osteoporosis is considered an important quality of care indicator, used by the majority of health plans in the USA to measure performance of the health care system [www.ncqa.org].

In conclusion, we found that a multi-faceted intervention with a centralized osteoporosis coordinator is effective in improving osteoporosis care in smaller communities that do not have access to osteoporosis specialists, but there is still a care gap. There are number of ways in which this intervention could be improved. There could be better advertising of the program. For example, there could be pamphlets/posters in the waiting room and more importantly staff in the ED could mention to fracture patients the link between osteoporosis and fracture and that the hospital has a special program for fracture patients. Rates of BMD testing are higher than appropriate management suggesting that interventions in the future need to address issues with reporting and interpretation of bone density measurements and fracture risk in treatment decision making. Treatment rates might be higher if patients understood their BMD results better for example this could be achieved with a standardized report for the family physicians outlining fracture risk and treatment recommendations and a patient-specific BMD report. We also need to improve our efforts to disseminate information about the importance of osteoporosis in men to health care providers and clarify treatment recommendations. Finally, in terms of knowledge translation this intervention is best suited for a universal or managed care setting.

\footnotetext{
Acknowledgements SB Jaglal is the Toronto Rehabilitation Institute Chair at the University of Toronto; G Hawker is The Arthritis Society Senior Distinguished Rheumatology Investigator and FM Hill Chair in Academic Women's Medicine, Women's College Hospital; SM Cadarette holds a Canadian Institutes of Health Research New Investigator Award; SR Majumdar is an Alberta Heritage Foundation for Medical Research Health scholar. A Papaioannou holds the Eli Lilly Canada Chair in Osteoporosis. Dr. Marita Kloseck is the recipient of an unrestricted research grant from Procter \& Gamble. This study was funded by a grant from the Ontario Ministry of Health and Long-Term Care Osteoporosis Strategy. Research at Toronto Rehabilitation Institute is supported in part by funding under the Provincial Rehabilitation Research Program from the Ministry of Health and Long-Term Care in Ontario. The views expressed do not necessarily reflect those of the Ministry. Equipment and space have been funded with grants from the Canada Foundation for Innovation, Ontario Innovation Trust, and the Ministry of Research and Innovation. Trial Registration Number: ClinicalTrials.gov Identifier: NCT00511693.
}

Conflicts of interest None.

Open Access This article is distributed under the terms of the Creative Commons Attribution Noncommercial License which permits any noncommercial use, distribution, and reproduction in any medium, provided the original author(s) and source are credited.

\section{References}

1. Brown JP, Josse RG, Scientific Advisory Council of the Osteoporosis Society of Canada (2002) Clinical practice guidelines for the diagnosis and management of osteoporosis in Canada. CMAJ 167(10 Suppl):S1-S34

2. Papaioannou A, Morin S, Cheung AM, Atkinson S, Brown J, Feldman S, Hanley DA, Hodsman A, Jamal SA, Kaiser SM, Kvern B, Siminoski K, Leslie WD (2010) Clinical practice guidelines for the diagnosis and management of osteoporosis in Canada. CMAJ 2010. doi:10.1503/cmaj.100771

3. Center JR, Bliuc D, Nguyen TV, Eisman JA (2007) Risk of subsequent fracture after low-trauma fracture in men and women. JAMA 297(4):387-394

4. Elliot-Gibson V, Bogoch ER, Jamal SA, Beaton DE (2004) Practice patterns in the diagnosis and treatment of osteoporosis after a fragility fracture: a systematic review. Osteoporos Int 15(10):767-778

5. Giangregorio L, Papaioannou A, Cranney A, Zytaruk N, Adachi JD (2006) Fragility fractures and the osteoporosis care gap: an international phenomenon. Semin Arthritis Rheum 35(5):293-305

6. Heaney RP (2003) Advances in therapy for osteoporosis. Clin Med Res 1(2):93-99

7. Compston J (2004) Action Plan for the prevention of osteoporotic fractures in the European Community. Osteoporos Int 15:259-262

8. Curtis JR, Adachi JD, Saag KG (2009) Bridging the osteoporosis quality chasm. J Bone Min Res 24:3-7

9. Raisz LG, Elderkin AL, Schargorodski L, Hart T, Waldman C, King T, Noonan AS (2009) A call to action: developing and implementing a national action plan to improve bone health. Osteoporos Int 20:1805-1806

10. Jaglal SB, Hawker GA, Cameron C, Canavan J, Beaton DE, Bogoch E, Jain R, Papaioannou A, ORMEW working group (2010) The Ontario osteoporosis strategy: implementation of a population-based osteoporosis action plan in Canada. Osteoporos Int 21:903-908

11. Bogoch ER, Elliot-Gibson V, Beaton DE, Jamal SA, Josse RG, Murray TM (2006) Effective initiation of osteoporosis diagnosis and treatment for patients with a fragility fracture in an orthopaedic environment. J Bone Joint Surg Am 88(1):25-34

12. Solomon DH, Finkelstein JS, Polinski JM, Arnold M, Licari A, Cabral D, Canning C, Avorn J, Katz JN (2006) A randomized controlled trial of mailed osteoporosis education to older adults. Osteoporos Int 17:760-767

13. Bliuc D, Eisman JA, Center JR (2006) A randomized study of two different information-based interventions on the management of osteoporosis in minimal and moderate trauma fractures. Osteoporos Int 17(9):1309-1317

14. Jaglal SB, Hawker G, Bansod V, Salbach NM, Zwarenstein M, Carroll J, Brooks D, Cameron C, Bogoch E, Jaakkimainen L, Kreder H (2009) A demonstration project of a multi-component educational intervention to improve integrated post-fracture osteoporosis care in five rural communities in Ontario, Canada. Osteoporos Int 20:265-274

15. Gardner MJ, Brophy RH, Demetrakopoulos D, Koob J, Hong R, Rana A, Lin JT, Lane JM (2005) Interventions to improve 
osteoporosis treatment following hip fracture. A prospective, randomized trial. J Bone Joint Surg Am 87(1):3-7

16. Feldstein A, Elmer PJ, Smith DH, Herson M, Orwoll E, Chen C, Aickin M, Swain MC (2006) Electronic medical record reminder improves osteoporosis management after a fracture: a randomized, controlled trial. J Am Geriatr Soc 54(3):450-457

17. Davis JC, Guy P, Ashe MC, Liu-Ambrose T, Khan K (2007) HipWatch: osteoporosis investigation and treatment after a hip fracture: a 6-month randomized controlled trial. J Gerontol Series A 62:888-891

18. Majumdar S, Beaupre LA, Harlery $\mathrm{CH}$, Hanley DA, Lier DA, Juby AG, Maksymowych WP, Cinats JG, Bell NR, Morrish DW (2007) Use of a case manager to improve osteoporosis treatment after hip fracture: results of a randomized controlled trial. Arch Intern Med 167:2110-2115

19. Solomon DH, Polinski JM, Stedman M, Truppo C, Breiner L, Egan C, Jan S, Patel M, Weiss TW, Chen YT (2007) Improving care of patients at-risk for osteoporosis: a randomized controlled trial. J Gen Intern Med 22:362-367

20. Cranney A, Lam M, Ruhland L, Brison R, Godwin M, Harrison MM, Harrison MB, Anastassiades T, Grimshaw JM, Graham ID (2008) A multifaceted intervention to improve treatment of osteoporosis in postmenopausal women with wrist fractures: a cluster randomized trial. Osteopor Int 19:1733-1740

21. Majumdar SR, Johnson JA, McAlister FA, Bellerose D, Russell AS, Hanley DA, Morrish DW, Maksymowych WP, Rowe BH (2008) Multifaceted intervention to improve diagnosis and treatment of osteoporosis in patients with recent wrist fracture: a randomized controlled trial. CMAJ 178:569-575

22. Miki RA, Oetgen ME, Kirk J, Insogna KL, Lindskog DM (2008) Orthopaedic management improves the rate of early osteoporosis treatment after hip fracture: a randomized clinical trial. J Bone Jt Surg- A 90:2346-2353

23. Rozental TD, Makhni EC, Day CS, Bouxsein ML, Rozental TD, Makhni EC, Day CS, Bouxsein ML (2008) Improving evaluation and treatment for osteoporosis following distal radial fractures: a prospective randomized intervention. J Bone Jt Surg-Am 90:953-961

24. Little EA, Eccles MP (2010) A systematic review of the effectiveness of interventions to improve post-fracture investigation and management of patients at risk of osteoporosis. Implem Sci 5:80. doi:10.1186/1748-5908-5-80

25. Dickson L, Cameron C, Hawker G, Ratansi A, Radziunas I, Bansod V, Jaglal S (2008) Development of a multidisciplinary osteoporosis telehealth program. Telemedicine e-Health 14 (5): $473-478$

26. Siminoski K, Leslie WD, Frame H, Hodsman A, Josse RG, Khan A, Lentle BC, Lévesque J, Lyons DJ, Tarulli G, Brown JP (2005) Recommendations for bone mineral density reporting in Canada. Can Assoc Radiol J 56(3):178-188

27. Brown JP, Fortier M (2006) Canadian Consensus Conference on Osteoporosis 2006 Update. JOGC 172:S95-S112

28. Majumdar SR, Rowe BH, Folk D, Johnson JA, Holroyd BH, Morrish DW, Maksymowych WP, Steiner IP, Harley CH, Wirzba
B, Hanley DA, Blitz S, Russell AS (2004) A controlled trial to increase detection and treatment of osteoporosis in older patients with a wrist fracture. Annals Intern Med 141:366-373

29. Cadarette SM, Jaglal SB, Raman-Wilms L, Beaton DE, Paterson JM (2010) Osteoporosis quality indicators using healthcare utilization data. Osteoporos Int. doi:10.1007/s00198-010-1329-8

30. Cadarette SM, Beaton DE, Gignac MAM, Jaglal SB, Dickson L, Hawker GA (2007) Minimal error in self-report of having had DXA, but self-report of its results was poor. J Clin Epidemiol 60:1306-1311

31. Majumdar SR, Johnson JA, Lier DA, Russell AS, Hanley DA, Blitz S, Steiner IP, Maksymowych WP, Morrish DW, Holroyd BR, Rowe BH (2007) Persistence, reproducibility, and costeffectiveness of an intervention to improve the quality of osteoporosis care after a fracture of the wrist: results of a controlled trial. Osteoporosis Int 18:261-270

32. Campbell MK, Mollison J, Grimshaw JM (2001) Cluster trials in implementation research: estimation of intracluster correlation coefficients and sample size. Stat Med 20(3):391-399

33. Donner A, Klar N (2000) Design and analysis of cluster randomization trials in health research. Arnold, London

34. Liang KY, Zeger S (1986) Longitudinal data analysis using generalized linear models. Biometrika 73:13-22

35. Højsgaard S, Halekoh U, Yan J (2005) The R package geepack for generalized estimating equations. J Statistical Software 15:1-11

36. R Development Core Team (2008) R: A Language and Environment for Statistical Computing. R Foundation for Statistical Computing, Vienna, Austria

37. Moher D, Hopewell S, Schulz KF, Montori V, Gøtzsche PC, Devereaux PJ, Elbourne D, Egger M, Altman DG (2010) CONSORT 2010 Explanation and Elaboration: updated guidelines for reporting parallel group randomised trials. BMJ 340:c869

38. Papaioannou A, Kennedy CC, Ioannidis G, Gao Y, Sawka AM, Goltzman D, Tenenhouse A, Pickard L, Olszynski WP, Davison KS, Kaiser S, Josse RG, Kreiger N, Hanley DA, Prior JC, Brown JP, Anastassiades T, Adachi JD (2008) The osteoporosis care gap in men with fragility fractures: the Canadian Multicentre Osteoporosis Study. Osteopor Int 19:581-587

39. Otmar R, Henry MJ, Kotowicz MA, Nicholson GC, Kirn S, Pasco JA (2011) Patterns of treatment in Australian men following fracture. Osteopor Int 22:249-254

40. Sedlak CA, Doheny MO, Estok PJ (2000) Osteoporosis in older men: knowledge and health beliefs. Orthop Nurs 19(38-42):44-46

41. Jaglal SB, Carroll J, Hawker G, McIsaac W, Jaakkimainen, Cadarette S, Cameron C, Davis D (2003) How are family physicians managing osteoporosis? Qualitative study of their experiences and educational needs. Can Family Phys 49:462-468

42. Papaioannou A, Morin S, Cheung AM, Atkinson S, Brown JP, Feldman S, Hanley DA, Hodsman A, Jamal SA, Kaiser SM, Kvern B, Siminoski K, Leslie WD, for the Scientific Advisory Council of Osteoporosis Canada 2010 (2010) Clinical practice guidelines for the diagnosis and management of osteoporosis in Canada: summary. CMAJ. doi:10.1503/cmaj.100771 